\title{
Transposition of great arteries with total anomalous pulmonary venous connection: A modified Senning procedure for late presentation
} \author{
India
}

Amit Mishra, MCh, FPCS, ${ }^{\mathrm{a}}$ Pankaj Garg, MCh, ${ }^{\mathrm{a}}$ Vishal Agarwal, MCh, ${ }^{\mathrm{a}}$ and Yashpal Rana, MD, ${ }^{\mathrm{b}}$ Gujarat,

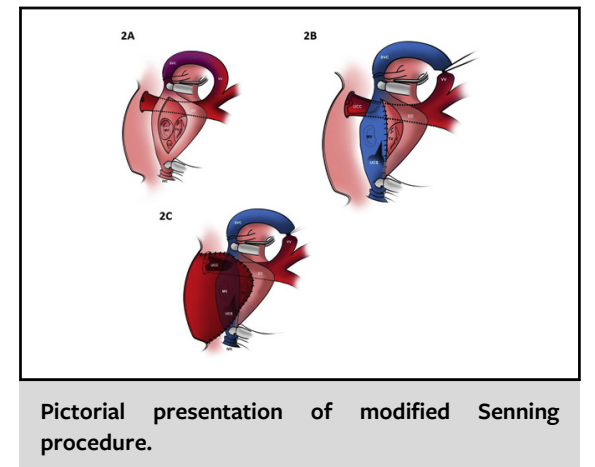

CENTRAL MESSAGE

In the rare, late presentation of $\mathrm{d}$ TGA with TAPVC, a modified senning provides excellent and durable outcomes.

See Commentaries on pages 227, 229, and 230
Cardiac surgeons frequently deal with transposition of the great arteries (d-TGA) and total anomalous pulmonary venous connection (TAPVC), common cyanotic congenital heart diseases (CHDs). However, the association of d-TGA with TAPVC is rare. It is a medical condition that arises when the pulmonary venous blood is delivered to the systemic ventricle without pulmonary overcirculation. The blood flowing to the left ventricle is delivered through the atrial septal defect. This complex association leads to late clinical presentation and faster regression of the left ventricle. Here, we present a simple and effective surgical technique of the modified Senning operation for the aforementioned condition.

\section{METHODS}

From April 2006 to December 2016, 4 patients were diagnosed both with d-TGA and TAPVC after they had symptoms of cyanosis. Informed consent was obtained from all 4 patients or their guardians. A 7-monthold infant diagnosed with d-TGA with coronary sinus type TAPVC and multiple ventricular septal defects underwent anatomical correction, whereas the other 3 patients, aged 7, 9, and 22 years, respectively, had a similar case history, where echocardiography reflected d-TGA with an intact interventricular septum with supracardiac TAPVC (Figure 1, B). This diagnosis was confirmed with a computed tomography scan with 3dimensional reconstruction (Figure 1, $A$ and $B$ ). These patients underwent a modified Senning procedure for which minor modifications were done for the unroofing of the common chamber.

\section{Surgical \\ Technique (Video 1)}

Once the sternotomy diagnosis of d-TGA with and supracardiac TAPVC was confirmed, pulmonary artery pressures were checked. Via the technique of aortobicaval cannulation, the vertical vein, superior vena cava, and inferior vena cava were dissected extrapericardially and looped. During bypass, the left atrium was partially dissected off the common chamber from the right side to prevent entry into the left side of the pericardial cavity. Under cardioplegic arrest, the right atrium was opened parallel to the atrioventricular groove (Figure 2, A). Fossa ovalis tissue was excised and the coronary sinus was unroofed (Figure 2, $B$ ). The left ventricle and mitral valve were of adequate size. The vertical vein was comfortably well protected from air locking and the common pulmonary venous chamber was unroofed from the right side (Figure 2, B). The posterior edge of right atriotomy was sutured to the anterior margin of fossa ovalis (Figure 2, B).

Subsequently, the superior vena cava, inferior vena cava, and coronary sinus blood was diverted to the mitral valve and left ventricle. The anterior edge of the atriotomy was sutured to the pericardium in situ. Then, the pulmonary venous blood was diverted to the tricuspid valve and right ventricle (Figure 2, C). Bypass was weaned off and the vertical vein was ligated. Transesophageal contrast echocardiography confirmed unobstructed flow in systemic and pulmonary venous pathways without any baffle leak.

\section{RESULTS}

The infant died of left ventricular dysfunction and pulmonary arterial hypertension on the fourth postoperative 


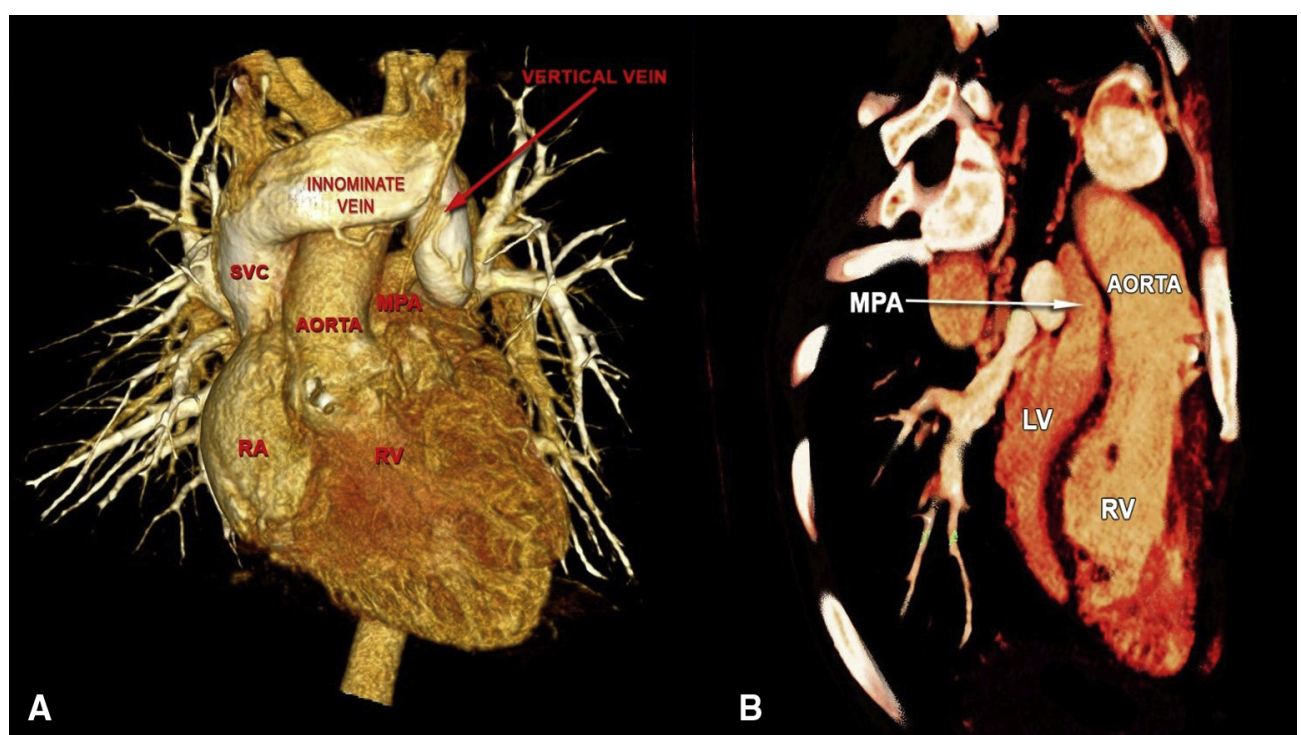

FIGURE 1. Preoperative computed tomographic images showing (A) extracardiac VRT images of d-TGA with supracardiac TAPVC. B, d-TGA with regressed left ventricle. $S V C$, Superior vena cava; $M P A$, main pulmonary artery; $R A$, right atrium; $R V$, right ventricle; $L V$, left ventricle.

day. We believe that patient was not prepared for surgery, as he had systemic pulmonary artery pressures and d-TGA was detected during the surgery. The other 3 patients have good right ventricular function with mid-tricuspid valve regurgitation with no baffle obstruction or leak. During regular follow-up, a computed tomography scan with 3-dimensional reconstruction (Figure $3, A$ and $B$ ) confirmed the unobstructed flow in systemic and pulmonary venous baffles.

\section{DISCUSSION}

d-TGA is a common form of CHD, but its association with TAPVC is rare. Arterial switch operation (ASO) with repair of TAPVC is the ideal operation in this subset. ${ }^{1}$ The balance between the pulmonary and systemic blood flow is a critical factor in the overall pathophysiology

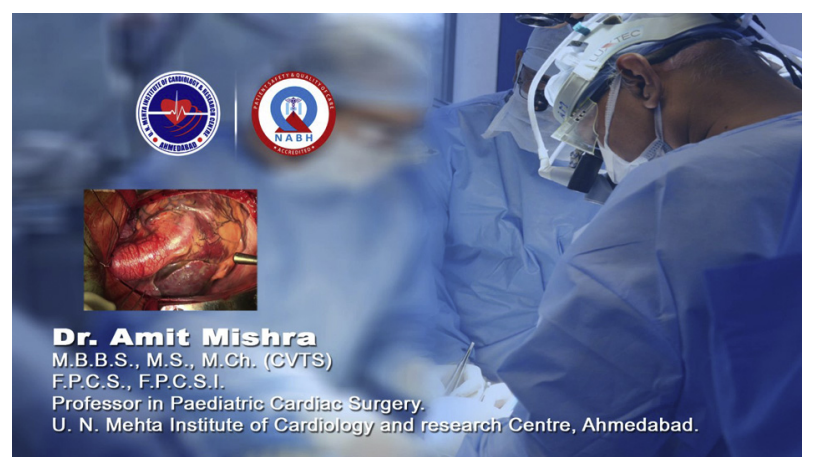

VIDEO 1. Modified Senning in a 22-year-old man with TGA with supracardiac TAPVC. Video available at: https://www.jtcvs.org/article/S26662507(20)30384-9/fulltext. of CHD. An isolated shunt lesion can cause severe symptoms in any patient when associated with unbalanced systemic/pulmonary circulation, whereas complex lesions may be asymptomatic if associated with balanced systemic and pulmonary circulation, as seen in this subset of d-TGA.

In 1933, d-TGA with TAPVC was first reported by Feldman and Chalmes, ${ }^{2}$ whereas the first in vivo description for it was made by Whitaker and colleagues. ${ }^{3}$ In 1972, Sapsford and colleagues ${ }^{4}$ performed the first successful Mustard operation for d-TGA with supracardiac TAPVC on a 16year-old girl. However, other authors have also performed a Senning operation using treated pericardium, similar to our procedure. ${ }^{5-7}$

The first successful ASO was performed by Mykychak and colleagues ${ }^{8}$ on a 5-hour-old baby who had d-TGA with infracardiac TAPVC, whereas Salve and colleagues ${ }^{1}$ also reported successful ASO in a 6-day-old baby with d-TGA and cardiac TAPVC. However, we observed that late presentation and early regression of the left ventricle served as limiting factors for ASO.

The presence of nonrestrictive ventricular septal defect with right-to-left shunt keeps the left ventricle prepared with good saturation. However, in its presence, the rapid development of pulmonary vascular disease has been associated with d-TGA. ${ }^{9}$ Perhaps this was the cause for severe left ventricular dysfunction and pulmonary vascular disease in our case one. We believe ASD's size restricts the pulmonary blood flow and prevents the pulmonary vascular disease in adolescent patients due to intact interventricular septum. All the aforementioned possibilities were considered while approaching the problem. 


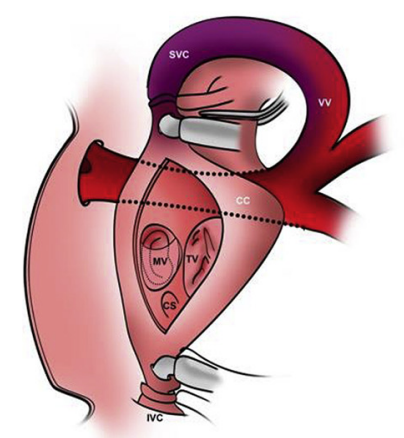

A

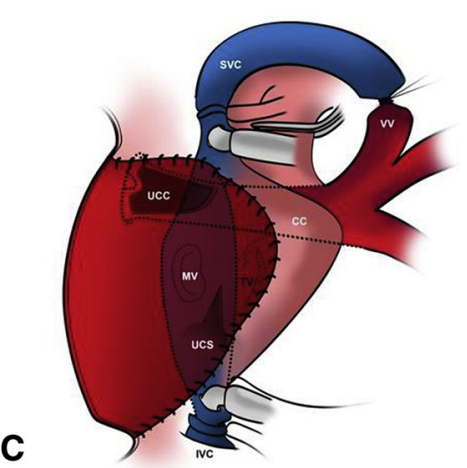

B

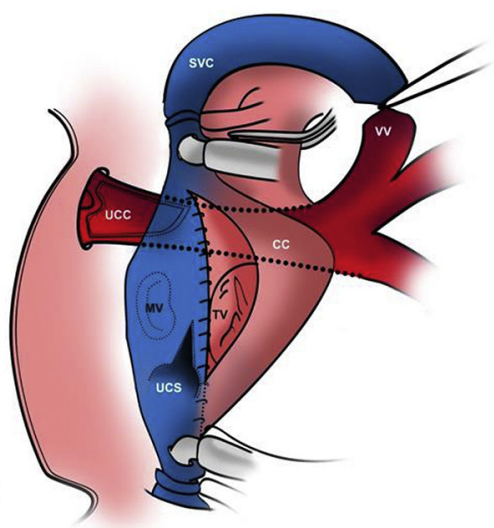

FIGURE 2. Pictorial presentation of modified Senning procedure showing (A) supracardiac TAPVC with VV draining to innominate vein and superior vena cava, and right atrial incision. (B) Comfortably well protected from air locking VV, excised fossa ovalis tissue. Unroofed right lateral aspect of common pulmonary venous chamber (UCC) and UCS, with completion of systemic venous baffle. C, Completion of pulmonary venous baffle using in situ pericardium and ligation of VV. $S V C$, Superior vena cava; $V V$, vertical vein; $C C$, common chamber; $M V$, mitral valve; $T V$, tricuspid valve; $C S$, coronary sinus; $I V C$, inferior vena cava; $U C C$, unroofed common chamber; $U C S$, unroofed coronary sinus.

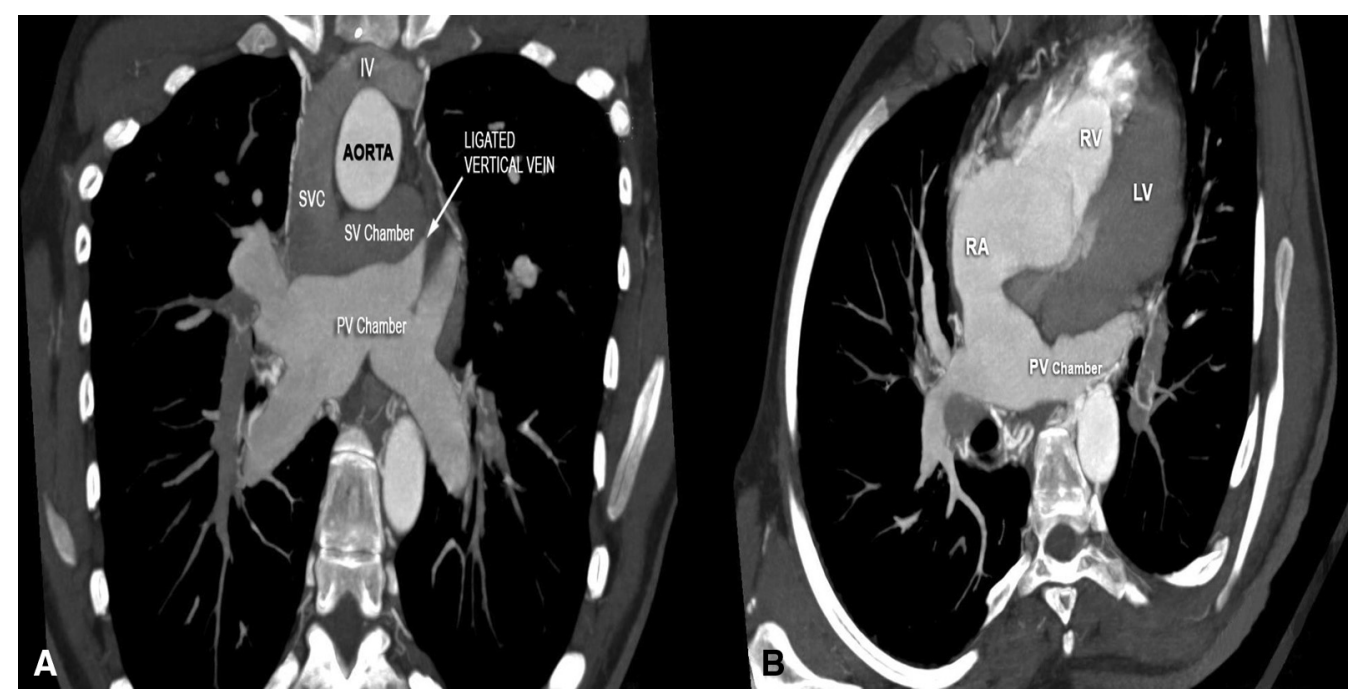

FIGURE 3. Postoperative computed tomographic images showing (A) unobstructed flow from pulmonary venous chamber to right atrium, right ventricle, and pulmonary artery and (B) new systemic and pulmonary venous chambers with unobstructed flow and ligated vertical vein. $I V$, Innominate vein; $S V C$, superior vena cava; $S V$ Chamber, systemic venous chamber; $P V$ Chamber, pulmonary venous chamber, $R V$, right ventricle; $L V$, left ventricle; $R A$, right atrium. 


\section{CONCLUSIONS}

It has been observed that early diagnosis and ASO are essential for the best result in these complex subsets of d-TGA. However, because of the complex pathophysiology of the disease and delayed clinical presentation, the modified Senning procedure is an ideal choice with limited risk.

The authors acknowledge the invaluable contribution of $\mathrm{Mr}$ Ashish Patel, Mr Piyush, and Mr Kirtan Patel for their uncannily lifelike operative illustrations and video editing, without which it would have been impossible to understand this complex procedure.

\section{References}

1. Salve GG, Jain SA, Dalvi BV, Shivaprakash K. Transposition of the great arteries with total anomalous pulmonary venous connection. Ann Thorac Surg. 2017;103: e349-51.

2. Feldman WH, Chalmes A. A case of complete transposition of the great vessels of the heart with a patent foramen ovale. Br J Child Dis. 1933;30:27.
3. Whitaker W, Watson DA, Keates PG. Total anomalous pulmonary venous drainage into the left innominate vein associated with transposition of the great vessels. Circulation. 1964;30:918-22.

4. Sapsford RN, Aberdeen E, Watson DA, Crew AD. Transposed great arteries combined with totally anomalous pulmonary veins. A report of a successful correction. J Thorac Cardiovasc Surg. 1972;63:360-6.

5. Barbero-Marcial M, Verginelli G, Vila J, Zerbini EJ. Transposition of the great arteries associated with total anomalous pulmonary venous connection: a surgical approach. Ann Thorac Surg. 1984;37:92-4.

6. Amodeo A, Corno A, Marino B, Carta MG, Marcelletti C. Combined repair of transposed great arteries and total anomalous pulmonary venous connection. Ann Thorac Surg. 1990;50:820-1.

7. Gontijo B, Fantini F, Barbosa M, Gomes MV, Gutierrez C, Vrandecic M. Surgical repair of transposition of great arteries and total anomalous pulmonary venous return to the coronary sinus (TGA with TAPVR). Eur J Cardiothorac Surg. 1994;8: 391-2.

8. Mykychak Y, Fedevych O, Maksymenko A, Yemets I. Simultaneous arterial switch and totally anomalous pulmonary venous connection repair in a 5-hourold child, complicated by pulmonary venous stenosis. Interact Cardiovasc Thorac Surg. 2017;24:809-10.

9. Kumar A, Taylor GP, Sandor GG, Patterson MW. Pulmonary vascular disease in neonates with transposition of the great arteries and intact ventricular septum. Br Heart J. 1993;69:442-5. 